Article

\title{
Scheduled Pre-Heating of Li-Ion Battery Packs for Balanced Temperature and State-of-Charge Distribution
}

\author{
Hien $\mathrm{Vu}^{1}{ }^{1}$ and Donghwa Shin ${ }^{2, *(\mathbb{D})}$ \\ 1 Department of Software Convergence, Soongsil University, Seoul 06978, Korea; hienvu@soongsil.ac.kr \\ 2 Department of Smart Systems Software, Soongsil University, Seoul 06978, Korea \\ * Correspondence: donghwashin@soongsil.ac.kr; Tel.: +82-2-820-0958
}

Received: 23 March 2020; Accepted: 29 April 2020; Published: 2 May 2020

check for updates

\begin{abstract}
Lithium-ion batteries exhibit significant performance degradation such as power/energy capacity loss and life cycle reduction in low-temperature conditions. Hence, the Li-ion battery pack is heated before usage to enhance its performance and lifetime. Recently, many internal heating methods have been proposed to provide fast and efficient pre-heating. However, the proposed methods only consider a combination of unit cells while the internal heating should be implemented for multiple groups within a battery pack. In this study, we investigated the possibility of timing control to simultaneously obtain balanced temperature and state of charge (SOC) between each cell by considering geometrical and thermal characteristics of the battery pack. The proposed method schedules the order and timing of the charge/discharge period for geometrical groups in a battery pack during internal pre-heating. We performed a pack-level simulation with realistic electro-thermal parameters of the unit battery cells by using the mutual pulse heating strategy for multi-layer geometry to acquire the highest heating efficiency. The simulation results for heating from $-30{ }^{\circ} \mathrm{C}$ to $10^{\circ} \mathrm{C}$ indicated that a balanced temperature-SOC status can be achieved via the proposed method. The temperature difference can be decreased to $0.38{ }^{\circ} \mathrm{C}$ and $0.19 \%$ of the SOC difference in a heating range of $40^{\circ} \mathrm{C}$ with only a maximum SOC loss of $2.71 \%$ at the end of pre-heating.
\end{abstract}

Keywords: battery pre-heating; lithium ion battery; mutual pulse heating; thermal model; battery cell grouping; dynamic battery model; idle period insertion

\section{Introduction}

Lithium-ion batteries are widely used for various battery-powered applications due to numerous technical advantages. The batteries are exposed or wrapped by a thin cover in varying temperature conditions in different applications, and thus the thermal management of the batteries in battery-powered applications including electric vehicles is an essential part of power system design [1].

Modern Li-ion batteries exhibit an explosive feature at high temperatures. Therefore, a thermal emergency should be avoided to maintain the safety of the applications. Furthermore, many studies revealed that higher temperature leads to excessive ageing of the battery [2]. Conversely, low temperature also leads to many problems. It is reported that a commercial 18650 lithium-ion battery can only provide $5 \%$ of nominal energy with $1.25 \%$ of power capacity at $-40{ }^{\circ} \mathrm{C}$ where the nominal capacity is determined at $20{ }^{\circ} \mathrm{C}$ [3]. Hence, the service quality of the battery-powered applications significantly deteriorates in low-temperature conditions. For example, the driving range of EVs significantly decreases in cold weather because the internal resistance of the batteries increases considerably at low temperature, and this results in heavy losses of energy and power capacity [4,5]. Additionally, lithium plating is a phenomenon wherein metallic lithium is formed around the anode 
of lithium-ion batteries during charging and is typically more prone to occur at low temperatures, thereby causing the rechargeable batteries to malfunction over time [6]. From a practical point of view, one of the major problems of the Li-ion battery to be handled in low temperature is that the cell is not able to provide sufficient power as required by the load. Thus, pre-heating plays an important role in practical perspectives.

In this study, we examined the possibility of timing control to simultaneously obtain a balanced temperature and SOC by considering the geometrical characteristics of a battery pack. The proposed method schedules the order and timing of the charge/discharge period for groups of cells in a battery pack during internal pre-heating. We performed pack-level simulation with realistic electro-thermal parameters of the lithium-ion $2500 \mathrm{mAh} \mathrm{LiNiMnCoO} 218650$ cells. The simulation results indicated that the proposed method can realize a balanced temperature-SOC condition over the pack when compared to conventional pre-heating methods without timing control.

The rest of this study is organized as follows. We introduce pre-heating methods of the battery pack and advantages of mutual pulse heating in Section 2. The non-uniform temperature distribution of the battery pack in internal heating and the concept of heating schedule are discussed in Section 3. The electrical characteristics of the lithium-ion battery at sub-zero temperatures and the thermal model of the battery pack are presented in Section 4 with a focus on the internal heat generation and lateral dependency of the battery pack. We discuss the optimization for the heating schedule method and evaluate the results in Section 5. Finally, we present the conclusions of the study and suggest future research directions in Section 6.

\section{Pre-Heating Methods for Battery Packs}

Extensive efforts were invested on pre-heating methods and they can be classified into two distinctive categories, namely external heating and internal heating [7]. The external heating methods utilize heaters deployed outside the battery pack that are powered by energy stored in the battery or external power source. There are many types of external heating systems that employ different physical mechanisms to provide simple heating solutions, such as convective heating or conductive heating, but they all require a particular battery management system (BMS) that combines different types of components for heat transfer (e.g., heaters and heat distribution systems), as illustrated in Figure 1a. However, conventional BMSs using external heating methods face significant challenges such as low heat transfer rate and low heating efficiency, especially for large scale battery structures [7]. Moreover, the critical issues of external heating in designing BMSs, such as temperature difference within the batteries inside the pack, can be addressed given the long heat transfer route or complex geometrical placement of heaters and heat distribution systems to decrease losses.
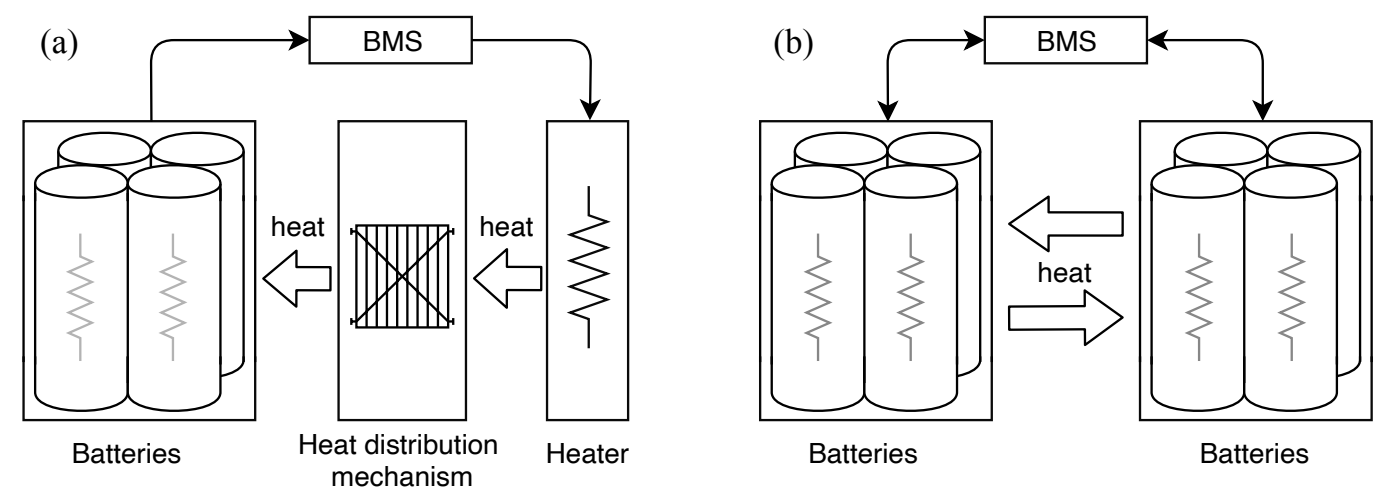

Figure 1. (a) External heating model. (b) Mutual pulse heating model.

In contrast to external heating, the internal heating method utilizes the high impedance of the cell as a heater at low temperature when the battery is being charged or discharged. Many studies focus on internal heating techniques and can be categorized into internal self-heating, mutual pulse heating, 
and alternating current heating. In these techniques, the heat source can be powered by either the battery pack or an external source that offers flexibility in system design level. A significant advantage of internal heating when compared to external heating is that the heat is generated inside the cell and directly warms it up without passing through any long heat transfer routes and reducing losses. The required heating time in internal heating is also shorter than that in most external heating strategies and varies from tens to hundreds of seconds [7].

Recently, internal mutual pulse heating method was proposed to provide high efficient pre-heating in sub-zero temperatures that offers fast warm-up time within $5 \mathrm{~min}$ while battery capacity of only $10 \%$ or less is consumed even when the electrical conversion efficiency is only $80 \%$ [8]. The technique uses the advantage of internal heat generation inside the cell without wasting heat on any intermediate heat transfer element. In this technique, the battery pack is divided into two groups with equal capacity. Then, heat is generated in the cells of both groups via transferring electrical power from one group to another as shown in Figure 1b. In the process, one group will be discharged while the other is charged. The charge/discharge roles of these groups are switched by a pulse signal to balance SOCs in the groups, and thereby avoiding over charge/discharge. In an interval, given that the required voltage for the charge group needs to be higher than the output voltage of the discharge group, the BMS acts as a bi-directional DC-DC boost converter to increase the charging voltage for one side and vice-versa for the other side in the next interval. The optimal pulse frequency and charge/discharge current rates were analysed in terms of pre-heating time and heating efficiency. Besides, the difference in initial SOC can be compensated by using mutual pulse heating that exhibits many advantages when compared to other internal heating methods [8]. The previous study successfully demonstrated the technical feasibility of internal heating methods via measurements. However, there is a paucity of studies on temperature uniformity for multiple groups of cells in a battery pack when using mutual pulse heating and on applying internal heating strategies.

\section{Heat Distribution Problem and Pre-Heating Schedule Strategy}

One of the primary challenges in pre-heating problems is to ensure the uniform heat distribution among the cells in the battery pack at the end of the process. In manufacturing, the battery is fabricated based on a pre-defined industrial electrical and mechanical standard, and thus the battery pack for a practical application is typically customized by assembling standard unit cells in a particular geometry to satisfy power requirements, and the cells are insulated by a casing with control and safety circuitry. In many applications, the battery packs are usually constructed from standard $18650 \mathrm{Li}$-ion unit cells with a typical structure, as shown in Figure 2. This structure is utilized for small battery packs, such as BB-2590 [9], or medium-size battery packs for portable applications.

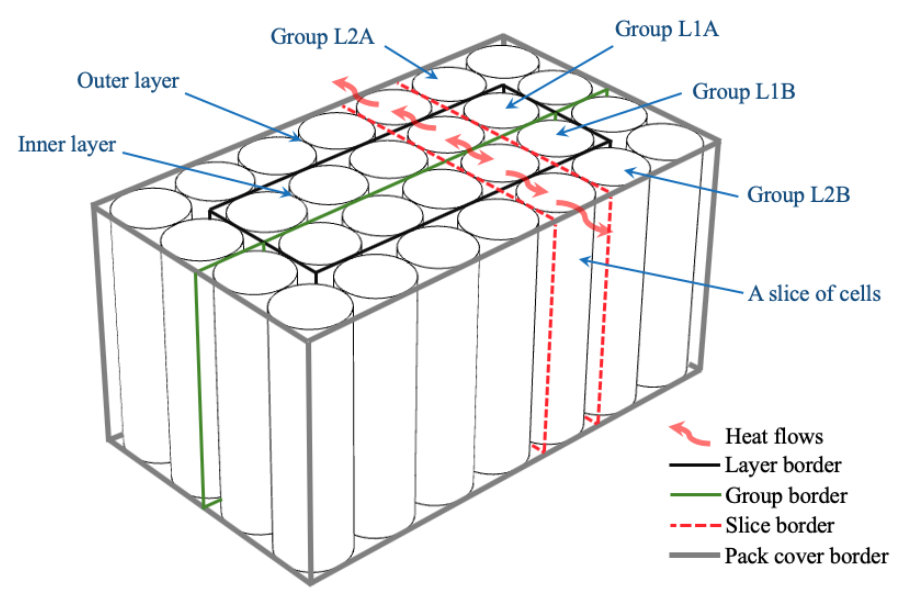

Figure 2. Pack geometry and heat flow in a battery pack consisting of Li-ion 18650 cells. 
Generally, the cells are arranged in a rectangular shape, and the outer cover is usually fabricated from a thermoplastic polymer to improve protection and heat insulation. However, when the same amount of charge/discharge current is applied to the unit cells to internally heat the pack, the outer layer of cells suffers higher losses, in terms of heat, to the outside environment than the inner layer due to differences in the areas of the pack cover, which is in contact with the outside environment. Thus, even within the same pack, the temperature of the inner layer $\left(T_{\text {Layer } 1}\right)$ exceeds the temperature of the outer layer $\left(T_{\text {Layer } 2}\right)$ and is above the target temperature $\left(T_{\text {target }}\right)$ at the end of heating process as illustrated in Figure 3a.

The significant dependency of the cell on temperature can result in poor electrical performance and accelerate degradation in battery pack capacity [10]. For example, in parallel-connected cells, one of the cells, which has a higher temperature, experiences a larger discharge current in the early stage of discharging. This is also known as the imbalance discharge phenomenon between cells [11]. Therefore, the difference in temperature between cells should be avoided before the battery pack is discharged.

In general, the previously proposed internal heating methods cannot achieve balanced SOCs and balanced temperatures at the end of pre-heating in the same time. The balanced SOCs and the same amount of internal heat generation are resulted from the same applied charge/discharge current over the pack in the pre-heating process. Nonetheless, the balanced temperature can only be achieved by creating different amounts of heat with different thermal characteristics. It is observed that obtaining both balanced temperature and SOCs is a contradictory objective when the whole pack is heated at the same time.

The only remaining controllable factor in the pre-heating procedure is the timing for activation of geometrical areas or timing control for each layer. Figure $3 \mathrm{~b}$ shows the changes in temperature when an idle period $\left(t_{\text {delay }}\right)$ is added to the pre-heating sequence of the outer layer. With activated mutual pulse heating, the inner layer is initially heated while the pre-heating process for the outer layer is started after the idle period. During the pre-heating process, both layers are heated for a certain duration $\left(t_{\text {heat }}\right)$ to ensure balanced SOCs. When the heating for the inner layer is stopped, it begins to lose heat to the outside environment to attain the same temperature with the outer layer at the end of the process. As a result, by varying the idle period, we can eliminate the difference in temperature between the two layers while ensuring the uniformity of SOCs.
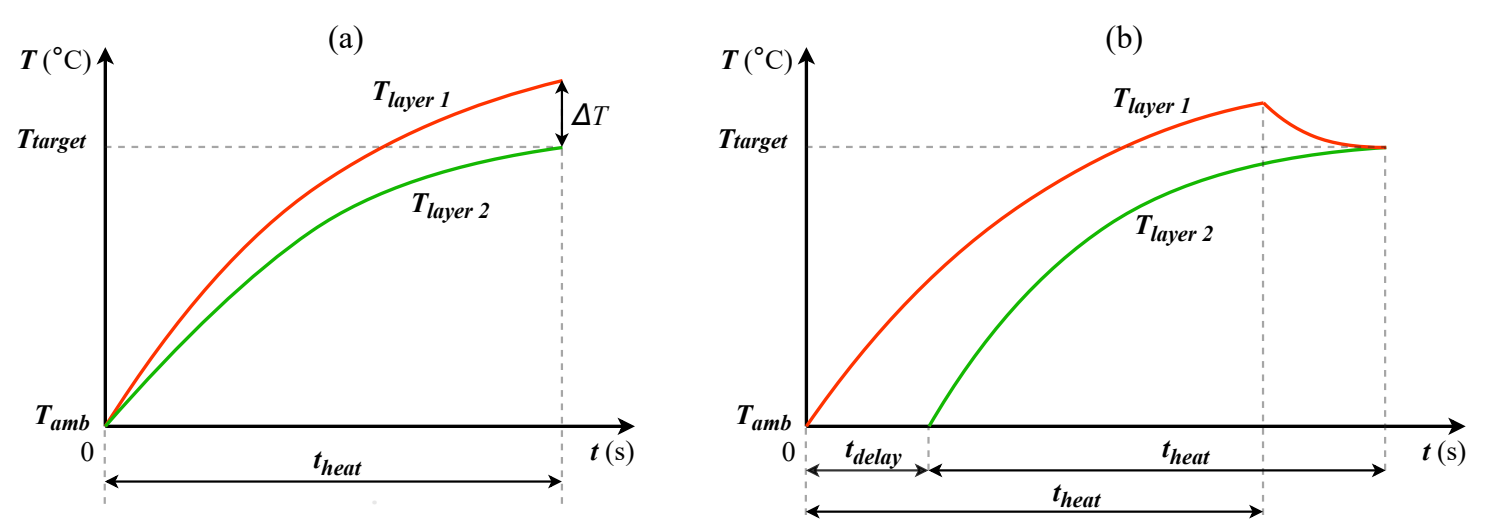

Figure 3. (a) Temperature imbalance between layers at the end of the conventional internal heating process. (b) Concept of temperature balancing by using the proposed heating schedule method.

In addition, when the same amount of charge/discharge current is applied alternately in mutual pulse heating, the variation in heat generated in the cells and SOC variation is expected to be extremely low when compared to that in other heating methods. The heat capacity of the units is also almost identical when we use a homogeneous structure.

Based on the battery structure in Figure 2, we divide the pack into two layers, and each layer is further divided into two groups with the same thermal characteristics. The cells of the inner layer are 
divided into two groups, namely $L 1 A$ and $L 1 B$ while the cells of the outer layer are also divided into two groups, namely $L 2 A$ and $L 2 B$, with the same electrical capacities. Two groups in the same layer are connected via a bi-directional DC-DC boost converter that performs a mutual pulse heating process. Two layers of cells require two independent converters that are controlled by a BMS and are activated separately to achieve optimal heating performance as demonstrated in Figure 4. The reference design for this converter is similar to the 4-switch buck-boost bi-directional DC-DC converter in battery backup power applications. In this study, the electrical conversion efficiency for each converter is set at $\eta_{\text {conv }}=80 \%$ which is lower than that in practical conditions.

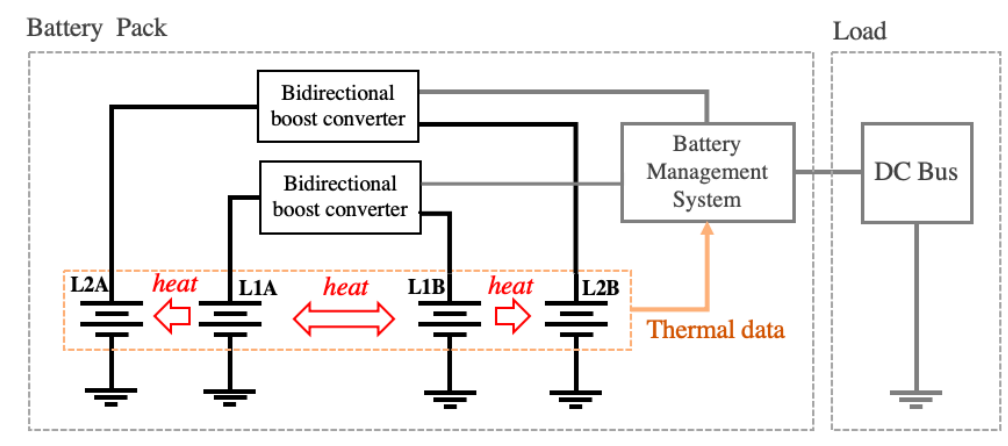

Figure 4. Electrical model with heat transfer between the groups and layers in a battery pack.

\section{Battery Pack Model and Behavior of a Lithium-Ion Battery at Sub-Zero Temperatures}

\subsection{Electrical Characteristics of a Unit Cell in Sub-Zero Temperatures}

In mutual pulse heating, the heat is generated by the internal impedance of a lithium-ion cell and it is subjected to change in different circumstances. Thus, an equivalent circuit model is required to evaluate the dependencies of the internal resistance on other factors and its effects on the pre-heating process in a sub-zero temperature environment.

Battery pack modelling begins with a systematic analysis of a single cell. Electrical characteristics of a lithium-ion cell were analysed in [12]. Accordingly, a single cell can be presented by a comprehensive equivalent circuit model as shown in Figure 5. In the model, the capacitor $C_{\text {ebat }}$ is the full-charge capacitor that represents the nominal electrical capacity of one cell, which corresponds to $100 \%$ of SOC. This capacitor can be charged/discharged via applying current to the terminal in the rightmost part of the circuit.

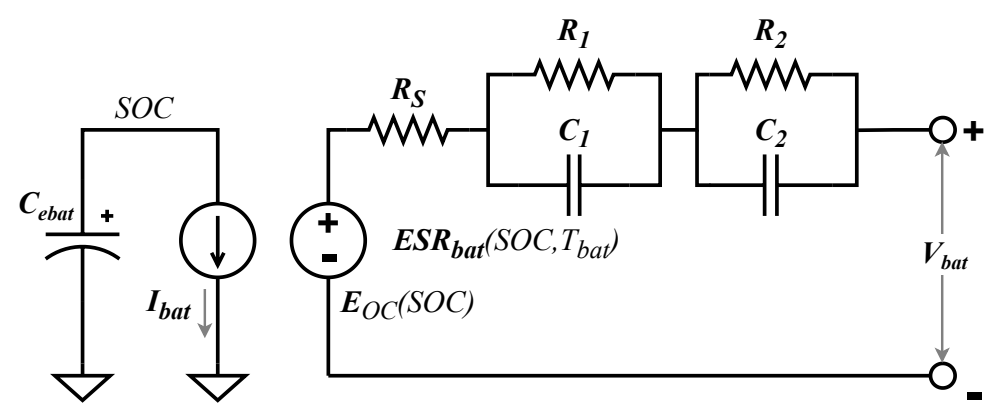

Figure 5. Equivalent circuit model for a Li-ion battery

The internal impedance of a cell consists of passive components, including a serial resistance $\left(R_{s}\right)$ and the parallel resistor-capacitor pairs, namely $R_{i}-C_{i}$, where $i$ denotes the $i$ th pairs. The terminal voltage $\left(V_{b a t}\right)$ is calculated from the open-circuit voltage $\left(E_{O C}\right)$, the internal impedance, and the battery 
current $\left(I_{b a t}\right)$. The open-circuit voltage is given as a function of $S O C$ and is expressed by the following nonlinear equation [13]:

$$
E_{O C}=b_{11} e^{b_{12} S O C}+b_{13} S O C^{4}+b_{15} S O C C^{2}+b_{16} S O C+b_{17}
$$

where $b_{i, j}$ is empirically-extracted regression coefficients [14], which are extracted by an extraction method in [15], and the parameters for the 18650 cells are listed in Table 1. Because the open-circuit voltage is SOC-dependent, the SOC is estimated by integrating the battery current with respect to time [16] as:

$$
S O C=S O C(0)-\frac{\int_{0}^{t} I_{b a t}(t) d t}{Q_{b a t}},
$$

where $S O C(0), Q_{b a t}$ and $I_{b a t}$ are the initial value of $S O C$ in percentage, the battery capacity in Ah, and charge/discharge current in A, respectively.

The internal heat of the cell is generated by the passive components. These components were examined in [17], that are given as functions of SOCs, battery temperature and battery current directions as follows:

$$
\begin{gathered}
R_{s, l}=R_{s, 0, l} \exp \left(\frac{T_{r e f R s, l}}{T_{b a t}-T_{\text {shiftRs }, l}}\right), \\
C_{i, l}=C_{0, i, l}+c_{1, i, l} S O C+c_{2, i, l} S O C^{2}+\left(c_{3, i, l}+c_{4, i, l} S O C+c_{5, i, l} S_{S O C}\right)^{2} T_{b a t}, \\
R_{i, l}=\left(R_{0, i, l}+a_{1, i, l} S O C+a_{2, i, l} S O C^{2}\right) \cdot \exp \left(\frac{T_{r e f R, i, 1}}{T_{b a t}-T_{\text {shift }, i, l}}\right), \\
i=\left\{\begin{array}{lll}
1, & \text { for } R_{1} \text { and } C_{1} \\
2, & \text { for } R_{2} \text { and } C_{2}
\end{array} \quad l=\left\{\begin{array}{ll}
c, & \text { charge } \\
d, & \text { discharge }
\end{array} .\right.\right.
\end{gathered}
$$

where $T_{b a t}$ are the battery temperature, $R_{0, i, l}, a_{1, i, l}, a_{2, i, l}, C_{0, i, l}, c_{1, i, l}, c_{2, i, l}, c_{3, i, l}, c_{4, i, l}$ and $c_{5, i, l}$ are parameters that are fitted via a second order polynomial for the SOC dependency, and $T_{r e f R, i, 1}$ and $T_{\text {shiftR,ill }}$ represent the temperature dependency.

In mutual pulse heating, DC conversions are employed to transfer the electrical energy back and forth from a group to another in the same layer. In this case, the batteries are continuously witched from the charging state to discharging state, and vice versa. Additionally, given that the values of the $R_{i}-C_{i}$ pairs tend to change inversely in charging and discharging depending on the SOCs [17], the opposite dependency of these passive components simultaneously occurs in the same heating interval, and thus the total equivalent series resistance $\left(E S R_{b a t}\right)$ in two groups remains unchanged in that interval. Furthermore, from pulse-relaxation tests under different SOCs, temperatures and current directions in [18], the $E S R_{\text {bat }}$ was revealed to exhibit minimal dependence on SOC, moderate dependence on current direction, and strong dependence on temperature. Therefore, we assume that the $E S R_{b a t}$ only depends on $T_{b a t}$ for simplicity.

The cell impedance was inspected further in recent studies. In [19], resistors $R_{1}$ and $R_{2}$ in Figure 5 remain unchanged during discharging in a wide range of temperatures from $-20^{\circ} \mathrm{C}$ to $5^{\circ} \mathrm{C}$ while serial resistance $\left(R_{S}\right)$ becomes a dominant part of the cell impedance. Based on $[17,20]$, the heat generation is calculated by using a single lumped internal resistance $\left(R_{b a t}\right)$ that includes heat dissipation through $R_{s}$ and $R_{i}-C_{i}$ pairs of the equivalent circuit model. The resistance was also examined in [18] for charging and discharging at different SOCs and indicated similar resistance-temperature dependence for a wide range of temperatures. Another study [21] revealed the relationship of internal impedance and the cell temperature for Li-ion 18650 cells in a sub-zero temperature range from $-30{ }^{\circ} \mathrm{C}$ to $0{ }^{\circ} \mathrm{C}$. On that account, we adopt and extend that dependence to $20^{\circ} \mathrm{C}$, as shown in Figure 6 . 


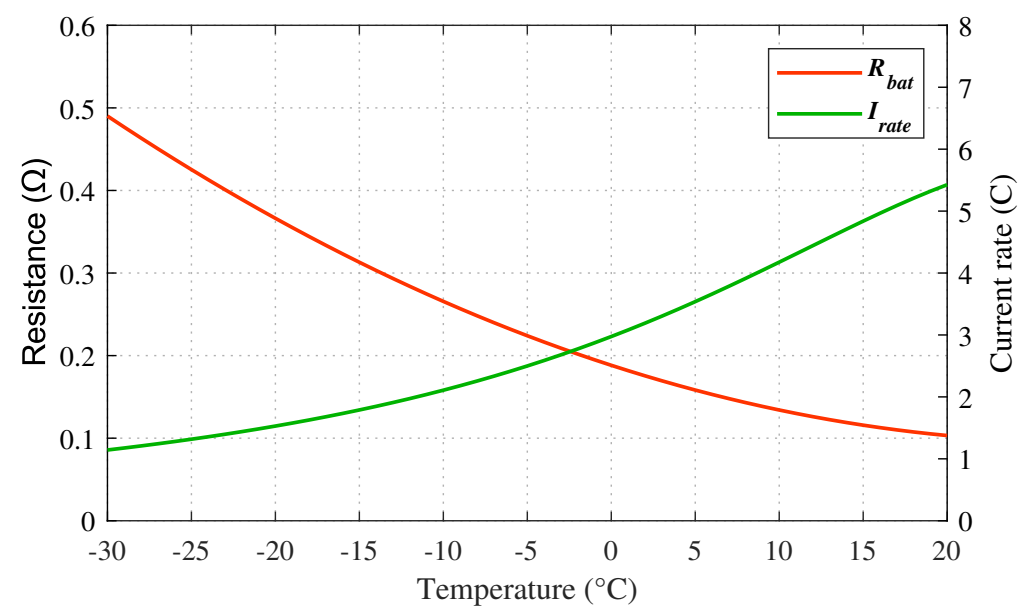

Figure 6. Internal resistance and maximum discharge rate while maintaining $V_{b a t}=2.8 \mathrm{~V}$ for a single Li-ion 18650 cell at different cell temperatures.

When a battery cell is discharged at a high rate in cold environment, the decrease in output voltage at the terminal of the cell can be excessively high due to the significant increase in internal resistance, thereby resulting in insufficient output power for the load. The effects of discharging a 18650 cylinder cell at different discharge rates on terminal voltage and battery temperature at $-15^{\circ} \mathrm{C}$ are demonstrated in Figure 7. During these discharge processes, the cell temperature rises and leads to the decrease of its internal resistance and thus the terminal voltage of the cell rises up by the time. Based on the voltage and temperature responses, increases in discharge current decrease heating time but also decrease discharge voltage. In mutual pulse heating, increases in discharge current from a group is the rise of charge current and charge voltage for another group. Furthermore, increases in the charge voltage can lead to the possibility of lithium plating on the anode of the cell [8]. Therefore, the terminal voltage should be maintained above a certain threshold voltage $\left(V_{t h r}\right)$. In this case, the battery can only be allowed to discharge at a certain magnitude based on its temperature that is represented as the maximum discharge rate $\left(I_{\text {rate }}\right)$ in Figure 6 and is determined by:

$$
I_{\text {rate }}=\frac{E_{O C}-V_{t h r}}{R_{b a t} Q_{b a t}}
$$

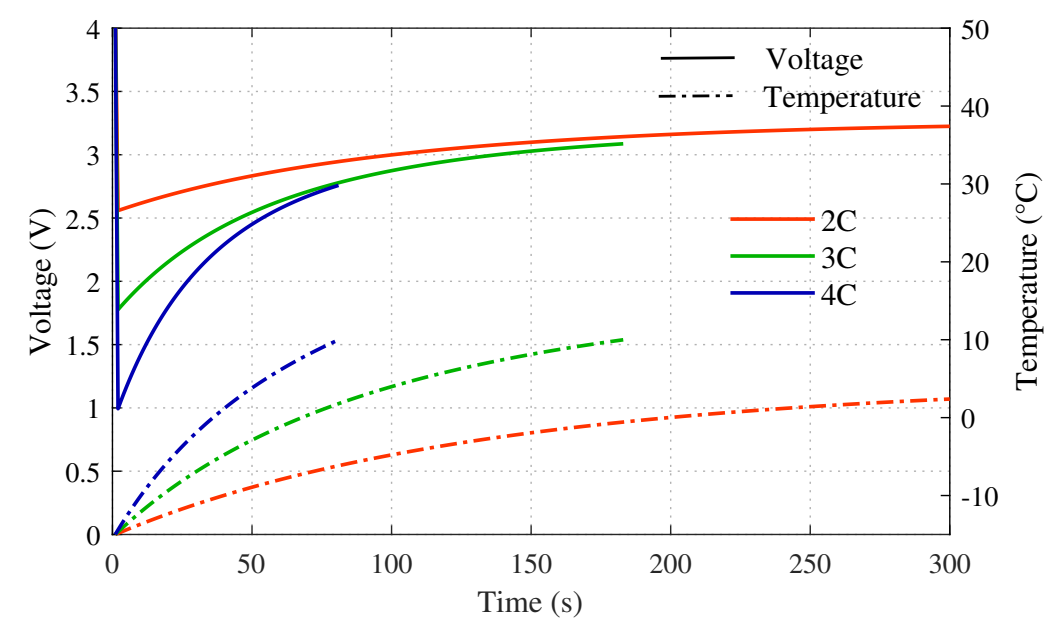

Figure 7. Terminal voltage and cell temperature responses at different discharge rates for a single Li-ion 18650 cell as heated from $-15^{\circ} \mathrm{C}$ to $10^{\circ} \mathrm{C}$ at different discharging currents. 


\subsection{Thermal Characteristics of a Unit Battery Cell}

Thermal model for a battery cell plays an important role in internal heating strategies. Hence, the heat generation in one cell is discussed in this sub-section. We use mechanical and electrical parameters for the Lithium-Ion $2500 \mathrm{mAh} \mathrm{LiNiMnCoO}_{2} 18650$ cell as reported in [21,22] and are listed in Table 1.

The thermal characteristics were reported in [19] by heating the battery cell using different alternating currents. Considering the given pack geometry in Figure 2, the space between the cylinder cells is filled with air. The pack cover acts as thermal insulation and prevents the air from circulating out of the pack and aids in eliminating the heat loss from convective heat transfer.

In general, because of the non-uniform internal temperature distribution in a cell, the thermal model of a lithium battery should be given in the form of a geometrical shape. It is reported that we can attain a sufficiently accurate result for a pack-level simulation with a lumped circuit model for targeted 18650 standard cells due to its sufficiently low internal temperature variation. In this study, each battery cell is assumed as a lumped circuit with uniform temperature distribution for simplicity.

The thermal balance of a battery cell with internal heat generation and external conduction were analysed in [23] and are expressed as:

$$
m C_{\text {bat }} \frac{\partial T_{\text {bat }}}{\partial t}=P_{g e n}-h_{b} A_{b s}\left(T_{b a t}-T_{a m b}\right)-\varepsilon \sigma A_{b s}\left(T_{b a t}^{4}-T_{a m b}^{4}\right)-Q_{e x t}
$$

where $m$ is the cell mass, $C_{b a t}$ is the specific heat capacity of a battery cell, $h_{b}$ and $A_{b s}$ are the heat transfer coefficient and battery surface area between the battery and surrounding air, $\varepsilon$ is the battery surface emissivity, $\sigma$ is the Stefan-Boltzmann constant, $T_{a m b}$ is the ambient temperature and $Q_{e x t}$ is external heat conduction from the connectors to the cell. In Equation (7), the elements on the right side represent the rate of internal heat generation, convective, radiation and conductive heat transfer rates, respectively. In the case of sub-zero temperatures, the radiation heat transfer rate is typically low when compared to convective heat transfer rate and is thus ignored in this study where temperature variables are significantly low [24]. In our battery pack model, cells in the same group are assumed to exhibit similar heat distribution and also for the connectors inside that group, and thus external heat conduction from the connectors to the battery is also ignored. For a single battery cell, the heat capacity is determined by:

$$
C_{b a t}=\rho_{c} V_{c} C_{p, c}+\rho_{a} V_{a} C_{p, a}+\rho_{s} V_{s} C_{p, s}
$$

where $\rho_{c, a, s}, V_{c, a, s}$ and $C_{p,\{c, a, s\}}$ are the density, volume, and specific heat capacities of the cathode, anode, and separator, respectively. The thermal parameters for a single Li-ion 18650 battery cell were reported in [22]. When considering a battery cell as a whole, the total heat generated by a Li-ion battery cell $\left(P_{\text {gen }}\right)$ can be divided into two elements, namely heat by overpotential $\left(Q_{p}\right)$ and heat by entropy change $\left(Q_{s}\right)$ as follows [25]:

$$
\begin{aligned}
P_{\text {gen }} & =Q_{p}+Q_{s}, \\
Q_{p} & =I_{b a t}^{2} R_{b a t}, \\
Q_{s} & =I_{b a t} T_{b a t} \frac{\partial E_{o c}}{\partial T_{b a t}} .
\end{aligned}
$$

Based on [26,27], the heat generated due to overpotential is exothermic during both charge and discharge cycles, and the heat generated due to entropy change is exothermic during the discharge cycle and endothermic during the charge cycle. In sub-zero temperatures, the heat $Q_{p}$ is typically exceeds heat $Q_{s}$ [24]. Therefore, the total heat generation from both processes are positive and the cell temperature increases during both charging and discharging processes. 


\subsection{Battery Pack Model with Lateral Thermal Dependency}

The heat transfer between a cell to another cell inside the battery pack and heat dissipation to the environment are simplified by using heat transfer models. Figure 8a illustrates the thermal model of a single cell and Figure $8 \mathrm{~b}$ shows the thermal model for a slice of cells. In these models, the heat capacitor $C_{b a t}$ is charged as heat is generated internally from $P_{g e n}$. Similarly, the heat capacitance of the cell decreases when the cell begins to lose heat through thermal resistors $R_{t b 2 a}, R_{b 2 a}$ and $R_{b 2 b}$. The heat transfer in the battery pack is modelled by analysing a slice of battery cutting through four groups of cells in a manner is similar to other slices in the battery pack. In the model, the heat dissipations from one cell to other cells that exhibit lower temperature and to the outside environment through the pack cover are also evaluated.

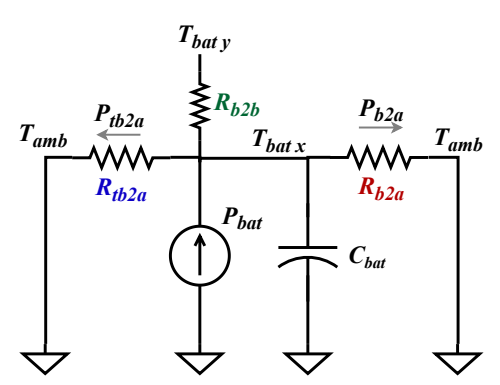

(a)

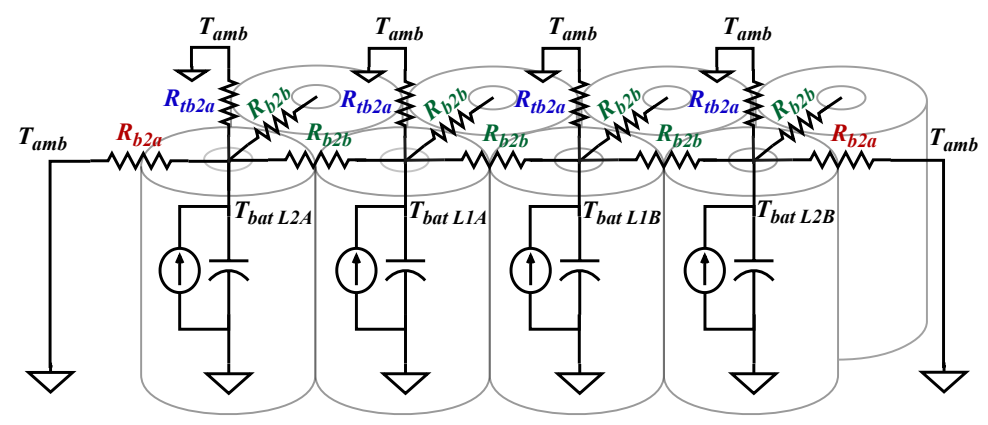

(b)

Figure 8. (a) Lumped RC-thermal circuit model for a unit cell. (b) Thermal RC network model for a slice in the battery pack.

As discussed in Section 3, we assuming that the battery pack is covered by a layer of thermoplastic polymer that has the same thickness distribution at every face to ensure the same thermal dissipation coefficient for the whole battery pack. The thermal resistance of the pack cover is divided into two parts: side area and top-bottom area corresponding to one cell in the slice. The thermal resistance of the side area is given as:

$$
R_{s b 2 a}=\frac{h_{\text {cover }}}{\lambda_{\text {Poly }} A_{s}}
$$

where $h_{\text {cover }}, \lambda_{\text {Poly }}$ and $A_{s}$ are the side cover thickness, polycarbonate thermal conductivity, and the area of the side area, respectively, in which the heat from a cell is dissipated to the air [28]. The thermal conductivity for polycarbonate was investigated in [29] and the cover thickness is assumed as presented in Table 1. The heat from the cells needs to dissipate through the cover layer before going out to the environment. Thus, the total thermal resistance from a cell to the outside environment through the pack cover is expressed as:

$$
R_{b 2 a}=R_{s b 2 a}+R_{b 2 b}
$$

where $R_{b 2 b}$ is defined as the thermal resistance from a cell to another cell through the air inside the pack, and was acquired from [25]. The thermal resistance of the pack cover for the top-bottom in an area corresponding to a cell is given by:

$$
R_{t b 2 a}=\frac{h_{\text {cover }}}{\lambda_{\text {Poly }} A_{t b}}
$$

where $A_{t b}$ is the total area of the top and bottom cover that face the air corresponding to a cell. We apply Equations (7), (11) and (12) for multiple-layer heat transfer to obtain the dynamic compact thermal model for one cell in the slice as follows: 


$$
P_{g e n_{i}}=m C_{b a t} \frac{\partial T_{b_{a t}}}{\partial t}+\frac{T_{b a t_{i}}-T_{a m b}}{R_{b 2 a}}+\frac{T_{b a t_{i}}-T_{a m b}}{R_{t b 2 a}}+\sum_{j=1}^{N} \frac{T_{b a t_{i}}-T_{b a t_{j}}}{R_{b 2 b}}
$$

where $i$ denotes the primary cell which is being modelled and $j$ denotes the $j$ th cell surrounding that primary cell. In Equation (13), the $P_{\text {gen }}$ is the source of heat while the elements on right-side represent the heat capacitance increment and losses to other cells and the outside environment. The parameters for the electrical and thermal models of the battery pack are summarized in Table 1.

Table 1. Parameters for battery models.

\begin{tabular}{cccccccc}
\hline \multicolumn{2}{c}{ Thermal Model } & \multicolumn{3}{c}{ Electrical Model } & \multicolumn{2}{c}{ Mechanical Model } \\
\hline Parameters & Values & Parameters & Values & Parameters & Values & Parameters & Values \\
\hline$\lambda_{\text {Poly }}$ & $0.22 \mathrm{~W} /(\mathrm{mK})$ & $Q_{\text {bat }}$ & $2.5 \mathrm{Ah}$ & $b_{16}$ & 1.6544 & $m_{\text {bat }}$ & $0.048 \mathrm{~kg}$ \\
$C_{b a t}$ & $1109 \mathrm{~J} /(\mathrm{kgK})$ & $b_{11}$ & -0.2653 & $b_{17}$ & 3.3564 & $h_{\text {bat }}$ & $65 \times 10^{-3} \mathrm{~m}$ \\
$R_{b 2 a}$ & $19.39 \mathrm{~K} / \mathrm{W}$ & $b_{12}$ & -61.6492 & $b_{21}$ & 0.0435 & $d_{\text {bat }}$ & $18 \times 10^{-3} \mathrm{~m}$ \\
$R_{b 2 b}$ & $10.84 \mathrm{~K} / \mathrm{W}$ & $b_{13}$ & -2.0398 & $b_{22}$ & -14.2753 & $h_{\text {cover }}$ & $2 \times 10^{-3} \mathrm{~m}$ \\
$R_{t b 2 a}$ & $34.402 \mathrm{~K} / \mathrm{W}$ & $b_{14}$ & 5.2765 & $b_{23}$ & 0.1537 & $A_{s}$ & $1.17 \times 10^{-3} \mathrm{~m}^{2}$ \\
& & $b_{15}$ & -4.1733 & $\eta_{\text {conv }}$ & $80 \%$ & $A_{t b}$ & $6.48 \times 10^{-4} \mathrm{~m}^{2}$ \\
\hline
\end{tabular}

\section{Experiments}

\subsection{Optimization for Thermal Balance and Pre-Heating Time}

In the proposed model, the lowest ambient temperature for examination corresponds to $-30{ }^{\circ} \mathrm{C}$. In addition to the restriction on the heating current by the temperature of the cell as stated in Equation (6), we set the maximum value of $I_{r a t e}$ at $3 C$ to increase the lifespan of the cell, which is lower than the heating rates in other internal heating methods. In practice, the target temperature of the warm-up process for lithium-ion battery should be higher than $0^{\circ} \mathrm{C}$ [7], and thus, we select the final heating temperature as $10^{\circ} \mathrm{C}$. Because the heating current is subjected to change based on the temperature of the cell, the ultimate factor for determining the final heating temperature $\left(T_{\text {final }}\right)$ is the heating duration $\left(t_{\text {heat }}\right)$. Therefore, in order to achieve the uniform temperature distribution and SOC balance at the same time, the dependencies of $t_{\text {heat }}$ and $t_{\text {delay }}$ on $T_{a m b}$ need to be investigated.

In the first scenario, we consider the dependency of the temperature difference at the end of the heating process $(\Delta T)$ on ambient temperature and duration of the idle period while remaining other parameters. By a trial and error simulation for the pack model at $T_{a m b}=-30{ }^{\circ} \mathrm{C}$, the heating duration is set as a constant $t_{\text {heat }}=580 \mathrm{~s}$. The relationship between the temperature difference and ambient temperature and duration of idle period is shown in Figure 9a.

As illustrated, the temperature difference between the two layers is decreased by changing the duration of the idle period. A cut through the plot at $\Delta T=0{ }^{\circ} \mathrm{C}$ reveals this relationship. This is not equivalent to a linear relationship, and thus a quadratic regression model is employed to represent the relationship as shown in Figure 9b, and its mathematical expression is as follows:

$$
t_{\text {delay }}=-0.125 T_{a m b}^{2}-1.65 T_{a m b}+109 .
$$

In the second scenario, the heating duration required to heat the battery pack to reach the target temperature corresponding to the ambient temperature is examined. We apply Equation (14) for $t_{\text {delay }}$ while varying $t_{\text {heat }}, T_{a m b}$ and remaining other factors. In this case, the final heating temperature is demonstrated in Figure 10a. Similarly, another regression model is used to present the dependency of $t_{\text {heat }}$ on $T_{\text {amb }}$ to meet $T_{\text {final }}=10^{\circ} \mathrm{C}$ as shown in Figure $10 \mathrm{~b}$ and expressed as:

$$
t_{\text {heat }}=0.5375 T_{a m b}^{2}+0.275 T_{a m b}+82.25 .
$$


The main objective is to minimize the temperature difference such that $\Delta T \approx 0{ }^{\circ} \mathrm{C}$ and maintain the final heating temperature $T_{\text {final }}=10^{\circ} \mathrm{C}$ in the range of $T_{a m b}$ from $-30{ }^{\circ} \mathrm{C}$ to $0{ }^{\circ} \mathrm{C}$. This can be done by refining the dependencies of $t_{\text {delay }}$ and $t_{\text {heat }}$ on $T_{a m b}$ through the previous scenarios but using the obtained dependencies instead of the constants.

(a)

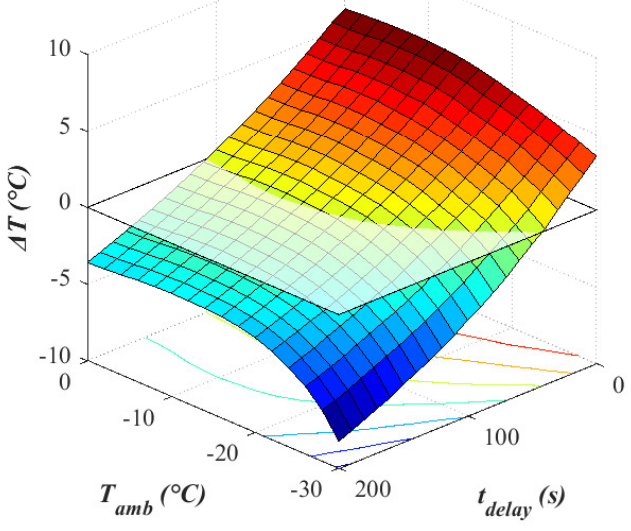

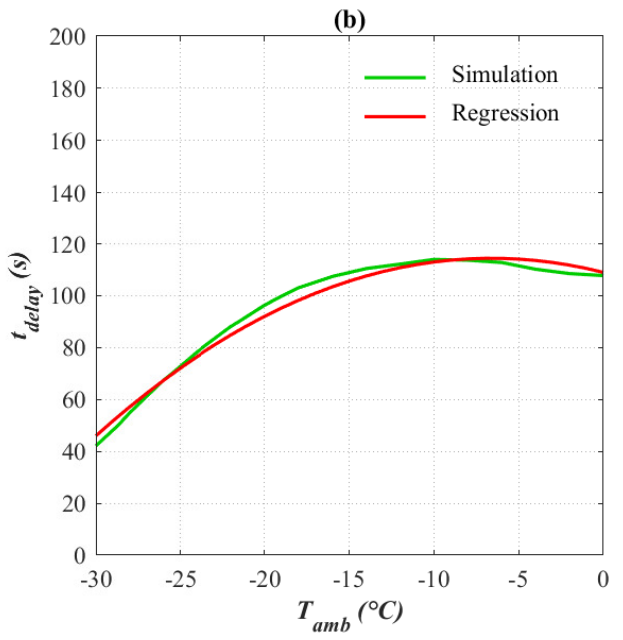

Figure 9. (a) Dependencies of the temperature difference $(\Delta T)$ between the layers on the duration of the idle period and ambient temperature at the end of pre-heating. (b) Relationships between the duration of idle period and the ambient temperature to achieve $\Delta T \approx 0{ }^{\circ} \mathrm{C}$ at the end of pre-heating.
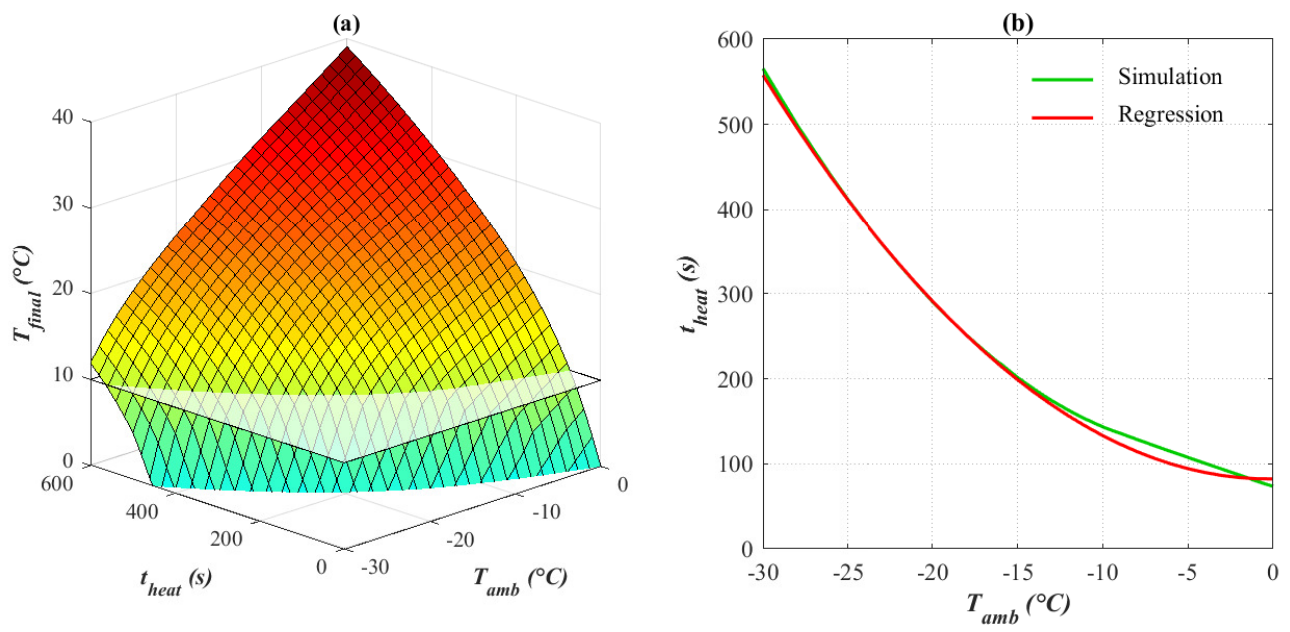

Figure 10. (a) Dependencies of the final temperature of the battery pack $\left(T_{\text {final }}\right)$ on heating time and ambient temperature. (b) Relationships between heating time and ambient temperature to get $T_{\text {final }}=10^{\circ} \mathrm{C}$.

\subsection{Results and Evaluation}

At a certain ambient temperature, the heating duration and idle period can be determined from the dependencies obtained previously. Heating by mutual pulse strategy at high initial SOC levels while using longer pulse intervals is likely to enlarge the risk of lithium plating [8]. Accordingly, the pulse frequency is maximized at $f_{\text {pulse }}=1 \mathrm{~Hz}$ in this study. The voltage, current, and temperature responses during mutual pulse heating from $T_{a m b}=-30{ }^{\circ} \mathrm{C}$ are shown in Figures 11 and 12 . With the restriction on the maximum heating current, the terminal voltage of the cell is maintained above $V_{t h r}=2.8 \mathrm{~V}$, and the current direction changes continuously to avoid over charge/discharge. During $1 \mathrm{~s}$ charge interval, the maximum terminal voltage of the cell quickly reaches $5.2 \mathrm{~V}$ but the lithium ion concentration on the graphite particle surface grows much slower at the anode-separator interface of 
the cell indicating safe operation free of Li plating. Therefore, the high terminal voltage of the cell in a short duration of charging is safe for the cell operation [8]. The temperature increases and a similar temperature at the end of the heating process in Figure 12 indicates the similarity to the proposed concept in Figure 3b. However, there are slight differences in the rates of rising temperature given the change in the internal resistance of the cell due to its temperature.

(a)

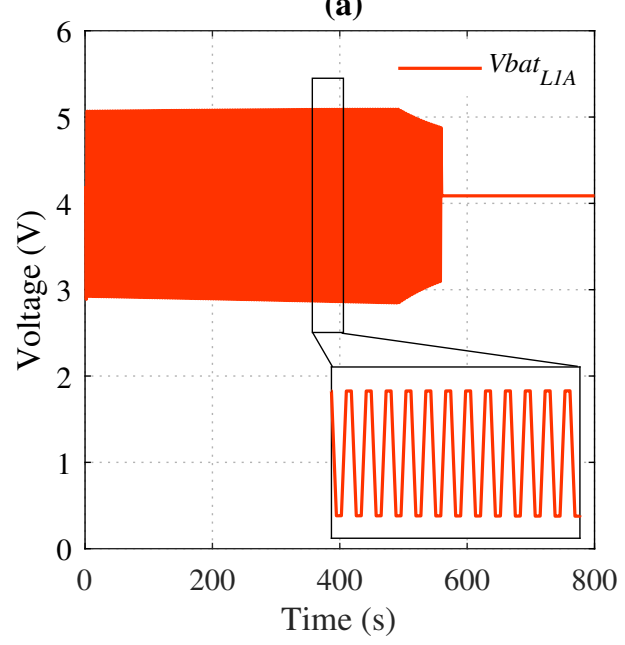

(b)

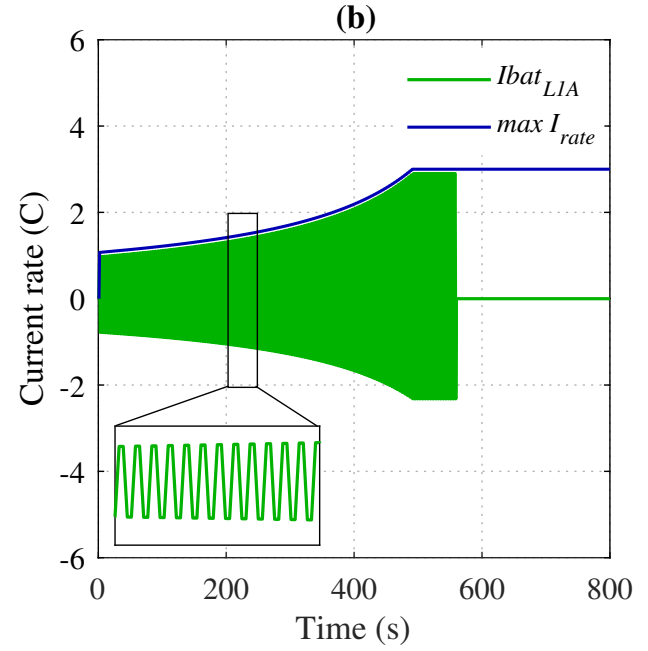

Figure 11. (a) Voltage response and (b) current response for one cell with $f_{\text {pulse }}=1 \mathrm{~Hz}$.

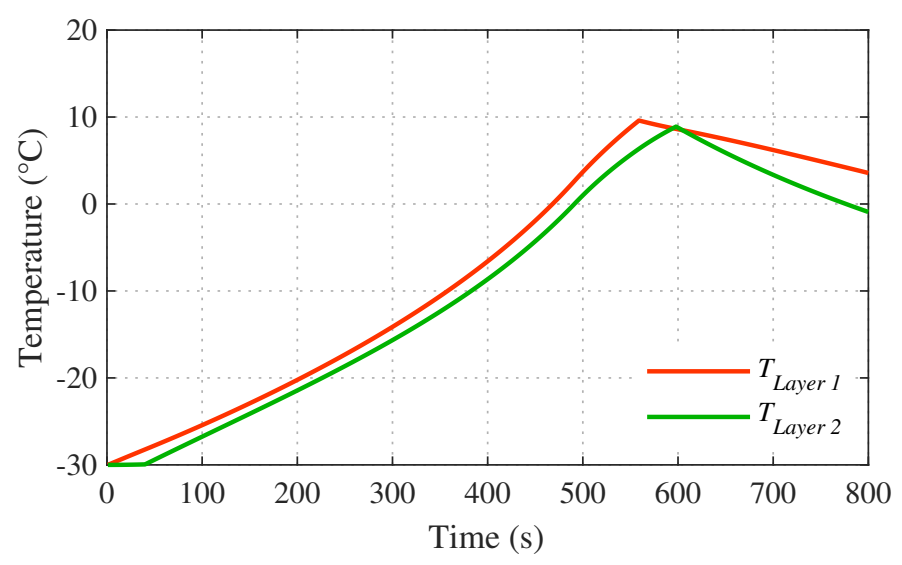

Figure 12. Temperature responses of two layers in the battery pack at $T_{a m b}=-30^{\circ} \mathrm{C}$.

Figure 13a shows the temperature difference between the inner layer and outer layer at the end of mutual pulse heating process at different ambient temperatures, in case of inserted and non-inserted the idle period. At extreme condition $T_{a m b}=-30{ }^{\circ} \mathrm{C}$, temperature difference is reduced by $3.0{ }^{\circ} \mathrm{C}$ (from $3.2^{\circ} \mathrm{C}$ to $-0.17^{\circ} \mathrm{C}$ ) by inserting the idle period. In general, the timing control method delivers better temperature uniformity when the temperature difference is lower than $0.38{ }^{\circ} \mathrm{C}$ for a wide range of ambient temperatures. The consumed SOC percentage $\left(S O C_{\text {loss }}\right)$ and $\mathrm{SOC}$ difference corresponding to the ambient temperature are shown in Figure 13b. As previously mentioned, when using mutual pulse heating, energy consumption is lower than $2.8 \%$ and the SOC difference is lower than $0.19 \%$ even in the case of a heating range of up to $40{ }^{\circ} \mathrm{C}$ (from $-30{ }^{\circ} \mathrm{C}$ to $10^{\circ} \mathrm{C}$ ) and the electrical conversion efficiency is set at only $80 \%$.

The required idle period for a specific battery pack can be summarized and stored in the form of a table in a system controller as listed in Table 2. It is noteworthy that that it is not a big burden for modern BMSs given their memory capacity and computational capability while they already store various types of tables to handle complicated electrochemical characteristics of the battery such as SOC-related I-V characteristics. 
(a)

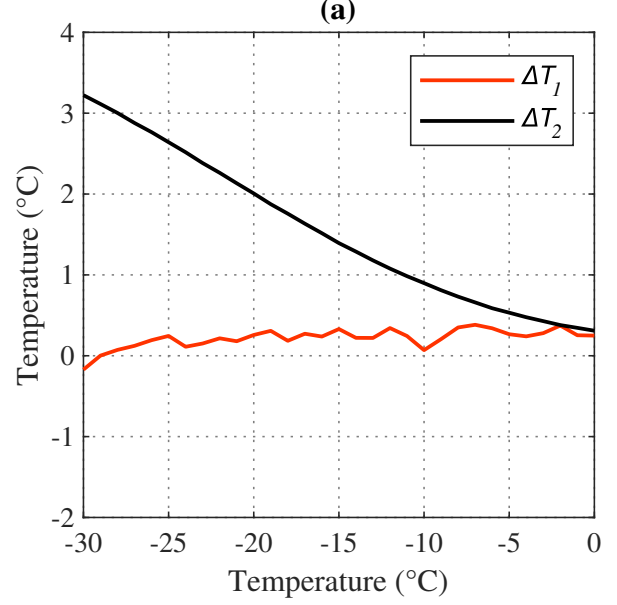

(b)

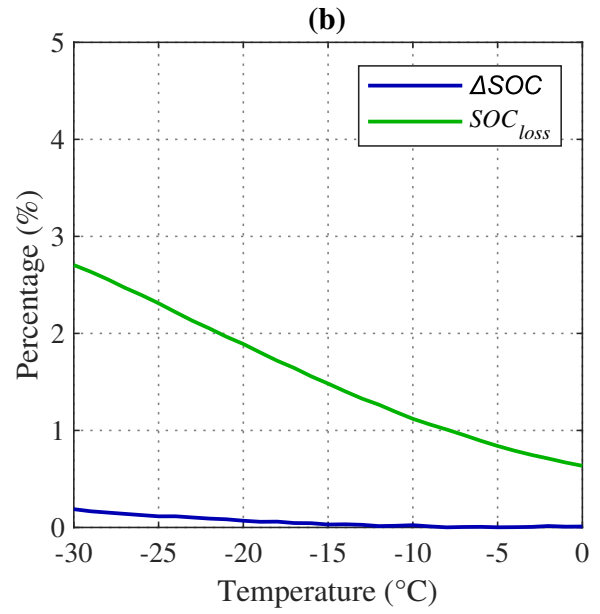

Figure 13. (a) Differences in temperature between layers at the end of pre-heating with $\left(\Delta T_{1}\right)$ and without $\left(\Delta T_{2}\right)$ the insertion of the idle period. (b) SOC difference between the layers and total SOC losses at the end of pre-heating by using the proposed method.

Table 2. Recommended charging profiles to $10^{\circ} \mathrm{C}$ with respect to $T_{a m b}$.

\begin{tabular}{ccccccc}
\hline $\boldsymbol{T}_{\boldsymbol{a m b}}\left({ }^{\circ} \mathbf{C}\right)$ & $\boldsymbol{I}_{\text {heat }}(\mathrm{C})$ & $\boldsymbol{t}_{\text {heat }}(\mathbf{s})$ & $\boldsymbol{t}_{\text {delay }}(\mathrm{s})$ & $\boldsymbol{T}_{\text {final }}\left({ }^{\circ} \mathrm{C}\right)$ & $\boldsymbol{\Delta} \mathbf{T}\left({ }^{\circ} \mathrm{C}\right)$ & $\Delta S O C(\%)$ \\
\hline-30 & 1.04 & 558 & 39 & 9.16 & -0.17 & 0.1881 \\
-25 & 1.22 & 429 & 30 & 9.57 & 0.25 & 0.1152 \\
-20 & 1.43 & 321 & 22 & 9.31 & 0.26 & 0.0692 \\
-15 & 1.69 & 232 & 16 & 8.76 & 0.33 & 0.0317 \\
-10 & 2.01 & 162 & 11 & 8.32 & 0.07 & 0.0235 \\
-5 & 2.40 & 111 & 8 & 8.78 & 0.27 & 0.0017 \\
0 & 2.88 & 80 & 6 & 10.03 & 0.25 & 0.0096 \\
\hline
\end{tabular}

\section{Conclusions}

Pre-heating a battery pack is essential under unpredictable weather conditions. Internal heating methods are widely examined because they are expected to provide fast heating time and low power consumption. However, given the variations in thermal characteristics of a single cell and the battery pack due to different pack geometries, the results indicate that it is difficult to simultaneously achieve a balanced temperature-SOC when we simply apply an internal heating method to the battery packs.

In this study, we show the possibility of timing control to attain a balanced temperature-SOC condition for pre-heating process. The order and timing of the charge/discharge period for the groups are controlled by inserting an idle period for the outer layer of the battery pack. The pack-level simulation with realistic parameters shows that the proposed method can obtain a balanced temperature-SOC condition over the pack with a slight increase in heating time. The proposed method reduces the temperature variation by $3.03^{\circ} \mathrm{C}$ when compared to conventional mutual pulse heating at ambient temperature $-30^{\circ} \mathrm{C}$, and maintaining the temperature difference under $0.38^{\circ} \mathrm{C}$ with the balanced SOCs in a wide range of ambient temperatures. The required idle period and heating duration with respect to the ambient temperature for an example pack geometry were also introduced. The presented framework can be applied for other specific battery packs without significant efforts, and the derived results as a lookup table can be easily embedded into modern BMSs.

Author Contributions: D.S. outlined the structure and content of this article. H.V. carried out the main experimental works and wrote the original draft. D.S. revised the manuscript. All authors have read and agreed to the published version of the manuscript.

Funding: This work was supported by the Soongsil University Research Fund (New Professor Support Research) of 2019.

Conflicts of Interest: The authors declare no conflict of interest. 


\section{References}

1. Karimi, G.; Li, X. Thermal management of lithium-ion batteries for electric vehicles. Int. J. Energy Res. 2013, 37, 13-24. [CrossRef]

2. Waldmann, T.; Wilka, M.; Kasper, M.; Fleischhammer, M.; Wohlfahrt-Mehrens, M. Temperature dependent ageing mechanisms in Lithium-ion batteries-A Post-Mortem study. J. Power Sources 2014, 262, 129-135. [CrossRef]

3. Nagasubramanian, G. Electrical characteristics of 18650 Li-ion cells at low temperatures. J. Appl. Electrochem. 2001, 31, 99-104. [CrossRef]

4. Remmlinger, J.; Buchholz, M.; Meiler, M.; Bernreuter, P.; Dietmayer, K. State-of-health monitoring of lithium-ion batteries in electric vehicles by on-board internal resistance estimation. J. Power Sources 2011, 196, 5357-5363. [CrossRef]

5. Ji, Y.; Zhang, Y.; Wang, C.Y. Li-Ion Cell Operation at Low Temperatures. J. Electrochem. Soc. 2013, 160, 636-649. [CrossRef]

6. Yang, X.G.; Leng, Y.; Zhang, G.; Ge, S.; Wang, C.Y. Modeling of lithium plating induced aging of lithium-ion batteries: Transition from linear to nonlinear aging. J. Power Source 2017, 360, 28-40. [CrossRef]

7. Hu, X.; Zheng, Y.; Howey, D.A.; Perez, H.; Foley, A.; Pecht, M. Battery warm-up methodologies at subzero temperatures for automotive applications: Recent advances and perspectives. Prog. Energy Combust. Sci. 2020, 77, 100806. [CrossRef]

8. Ji, Y.; Wang, C.Y. Heating strategies for Li-ion batteries operated from subzero temperatures. Electrochim. Acta 2013, 107, 664-674. [CrossRef]

9. Juzkow, M. Development of a BB-2590/U rechargeable lithium-ion battery. J. Power Sources 1999, 80, $286-292$. [CrossRef]

10. Chiu, K.C.; Lin, C.H.; Yeh, S.F.; Lin, Y.H.; Huang, C.S.; Chen, K.C. Cycle life analysis of series connected lithium-ion batteries with temperature difference. J. Power Sources 2014, 263, 75-84. [CrossRef]

11. Yang, N.; Zhang, X.; Shang, B.; Li, G. Unbalanced discharging and aging due to temperature differences among the cells in a lithium-ion battery pack with parallel combination. J. Power Sources 2016, 306, 733-741. [CrossRef]

12. Chen, M.; Rincon-Mora, G.A. Accurate electrical battery model capable of predicting runtime and I-V performance. IEEE Trans. Energy Convers. 2006, 21, 504-511. [CrossRef]

13. Shin, D.; Kim, K.; Chang, N.; Lee, W.; Wang, Y.; Xie, Q.; Pedram, M. Online estimation of the remaining energy capacity in mobile systems considering system-wide power consumption and battery characteristics. In Proceedings of the 2013 18th Asia and South Pacific Design Automation Conference (ASP-DAC), Yokohama, Japan, 22-25 January 2013. [CrossRef]

14. Lithium Ion Rechargeable Batteries Technical Handbook; Sony Corp.: Tokyo, Japan, 2007.

15. Petricca, M.; Shin, D.; Bocca, A.; Macii, A.; Macii, E.; Poncino, M. An automated framework for generating variable-accuracy battery models from datasheet information. In Proceedings of the International Symposium on Low Power Electronics and Design (ISLPED), Beijing, China, 4-6 September 2013. [CrossRef]

16. Kim, Y.; Mohan, S.; Siegel, J.B.; Stefanopoulou, A.G.; Ding, Y. The Estimation of Temperature Distribution in Cylindrical Battery Cells Under Unknown Cooling Conditions. IEEE Trans. Control Syst. Technol. 2014, 22, 2277-2286. [CrossRef]

17. Lin, X.; Perez, H.E.; Mohan, S.; Siegel, J.B.; Stefanopoulou, A.G.; Ding, Y.; Castanier, M.P. A lumped-parameter electro-thermal model for cylindrical batteries. J. Power Sources 2014, 257, 1-11. [CrossRef]

18. Mohan, S.; Kim, Y.; Stefanopoulou, A.G. Energy-Conscious Warm-Up of Li-Ion Cells From Subzero Temperatures. IEEE Trans. Ind. Electron. 2016, 63, 2954-2964. [CrossRef]

19. Zhang, J.; Ge, H.; Li, Z.; Ding, Z. Internal heating of lithium-ion batteries using alternating current based on the heat generation model in frequency domain. J. Power Sources 2015, 273, 1030-1037. [CrossRef]

20. Lin, X.; Perez, H.E.; Siegel, J.B.; Stefanopoulou, A.G.; Li, Y.; Anderson, R.D.; Ding, Y.; Castanier, M.P. Online parameterization of lumped thermal dynamics in cylindrical lithium ion batteries for core temperature estimation and health monitoring. IEEE Trans. Control Syst. Technol. 2013, 21, 1745-1755. [CrossRef] 
21. Shang, Y.; Xia, B.; Cui, N.; Zhang, C.; Mi, C.C. An Automotive Onboard AC Heater Without External Power Supplies for Lithium-Ion Batteries at Low Temperatures. IEEE Trans. Power Electron. 2018, 33, 7759-7769. [CrossRef]

22. Maleki, H.; Al Hallaj, S.; Selman, J.R.; Dinwiddie, R.B.; Wang, H. Thermal Properties of Lithium-Ion Battery and Components. J. Electrochem. Soc. 1999, 146, 947-954. [CrossRef]

23. Bernardi, D.; Pawlikowski, E.; Newman, J. A General Energy Balance for Battery Systems. J. Electrochem. Soc. 1985, 132, 5-12. [CrossRef]

24. Pesaran, A.A.; Vlahinos, A.; Burch, S.D. Thermal Performance of EV and HEV Battery Modules and Packs. In Proceedings of the 14th International Electric Vehicle Symposium; Electric Vehicle Association of the Americas: Orlando, FL, USA, 1997.

25. Onda, K.; Kameyama, H.; Hanamoto, T.; Ito, K. Experimental Study on Heat Generation Behavior of Small Lithium-Ion Secondary Batteries. J. Electrochem. Soc. 2003, 150, 285-291. [CrossRef]

26. Onda, K.; Ohshima, T.; Nakayama, M.; Fukuda, K.; Araki, T. Thermal behavior of small lithium-ion battery during rapid charge and discharge cycles. J. Power Sources 2006, 158, 535-542. [CrossRef]

27. Ye, Y.; Shi, Y.; Cai, N.; Lee, J.; He, X. Electro-thermal modeling and experimental validation for lithium ion battery. J. Power Sources 2012, 199, 227-238. [CrossRef]

28. Bejan, A.; Kraus, A.D. Heat Transfer Handbook; John Wiley \& Sons, Inc.: Hoboken, NJ, USA, 2003.

29. Weber, E.H.; Clingerman, M.L.; King, J.A. Thermally conductive nylon 6,6 and polycarbonate based resins. I. Synergistic effects of carbon fillers. J. Appl. Polym. Sci. 2003, 88, 112-122. [CrossRef]

(c) 2020 by the authors. Licensee MDPI, Basel, Switzerland. This article is an open access article distributed under the terms and conditions of the Creative Commons Attribution (CC BY) license (http://creativecommons.org/licenses/by/4.0/). 